\title{
Quantifying matrix cracking in composites by a thermoelastic method
}

by B. J. MAHONEY $\left({ }^{*}\right)$ and B. I. SANDOR $\left({ }^{*}\right)$

(*) Research Engineer, Road Load and Structures Test Department, Ford Motor Co., P.O. Box 2053, Dearborn, MI USA 48121.

$\left.{ }^{* *}\right)$ Professor, Department of Engineering Mechanics, University of Wisconsin-Madison, Madison, WI USA 53706.

\begin{abstract}
A new experimental and theoretical methodology has been developed to quantify transverse matrix cracking in composite laminates. A model was developed to relate changes in laminate longitudinal stiffness and Poisson's ratio to cyclically-induced temperature changes arising from the thermoelastic effect. Experiments have been performed to measure the above parameters in $\left(0_{3} / 90_{3}\right)_{s} \mathrm{Gl} / \mathrm{Ep}$ laminates, and very good correlations were observed between the results and theoretical predictions.
\end{abstract}

\section{Nomenclature}

$\begin{array}{ll}B & \text { Stefan-Boltzmann constant } \\ C_{\varepsilon} & \text { specific heat } \\ D & \text { damage parameter } \\ e & \text { emissivity } \\ E_{i i} & \text { lamina stiffness in } i \text { direction } \\ E_{i} & \text { original lamina stiffness in } i \text { direction } \\ E_{x x} & \text { laminate longitudinal stiffness } \\ E_{x x} & \text { normalized laminate longitudinal stiffness } \\ R & \text { load ratio } \\ t & \text { lamina thickness } \\ S & \text { TSA signal } \\ \bar{S} & \text { normalized TSA signal } \\ T_{o} & \text { average lamina temperature } \\ \alpha_{i} & \text { lamina CTE in } i \text { direction } \\ \alpha i & \text { original lamina CTE in } i \text { direction } \\ \Delta \sigma_{i} & \text { lamina stress in } i \text { direction } \\ \Delta \sigma_{x} & \text { non destructive cyclic stress range } \\ \Delta T^{o} & \text { thermoelastically-induced temperature change } \\ K & \text { laminate thermal diffusivity } \\ v_{12} & \text { lamina major Poisson's ratio } \\ v_{21} & \text { lamina minor Poisson's ratio } \\ v_{21}{ }^{\circ} & \text { original lamina minor Poisson's ratio } \\ v_{x y} & \text { laminate Poisson's ratio } \\ \bar{v}_{x y} & \text { normalized laminate Poisson's ratio } \\ \rho & \text { density } \\ \sigma_{d} & \text { damaging stress }\end{array}$

\section{Introduction}

The initial damage mechanism for composite laminates undergoing tension-tension cyclic loading is transverse intralaminar matrix cracking $[1,2]$. These cracks form in the off-axis plies 


\section{http://dx.doi.org/10.21611/qirt.1992.027}

and propagate quickly across the width of the laminate. Formation of the cracks does not constitute failure of the specimen, but instead results in a transfer of load to the principal loadcarrying plies. It is the failure of these plies which eventually results in the termination of specimen life [3].

It is well-established that longitudinal stiffness decreases with the development of transverse matrix cracks in cross-ply laminates [4]. Researchers have also shown that stiffness changes are directly correlated to a decrease in life for the damaged laminate. Stiffness change has thus proven to be a simple and powerful measure of damage, and most theoretical and experimental work in the area is focused on this. Yet it remains unclear how local stiffness changes are measured in specimens other than simple laboratory laminates. Other damage measures such as changes in Poisson's ratio [5] and coefficients of thermal expansion [6] are also difficult to measure for composite structures.

A new experimental and theoretical methodology has been developed to relate the evolution of matrix cracks in composite laminates to the thermoelastically-induced temperature change in cross-ply laminates using thermoelastic stress analysis (TSA). Changes in the TSA signal were also related to changes in laminate longitudinal stiffness $\left(E_{x x}\right)$ and Poisson's ratio $\left(v_{x y}\right)$ in $\left(\mathrm{O}_{3} / 90_{3}\right)_{\mathrm{s}} \mathrm{Gl} / \mathrm{Ep}$ laminates. This work provides an improved theoretical foundation for the behaviour first noted by ZHANG and SANDOR [7].

\section{Theoretical developments}

The TSA signal $S$ is measured using a sensitive detecting system employing a liquid nitrogen-cooled $\mathrm{HgCdTe}$ thermal detector. $S$ corresponds to changes in the infrared emission that result from the thermoelastically-induced temperature change $\Delta T$, and can be expressed as:

$$
S=\operatorname{eBf}(T) \frac{\Delta T}{T_{0}}
$$

where $e$ is the surface emissivity, $B$ is the Stefan-Boltzmann constant, $T_{o}$ is the average laminate temperature and $f(T)$ depends upon the thermal detector used in the system. POTTER and GREAVES [8] used the first and second laws of thermodynamics and the Helmholtz free energy to develop the general thermoelastic equation relating the deformation of an anisotropic material to $\Delta T$ :

$$
\frac{\Delta T}{T_{0}}=\frac{-1}{\rho C_{\varepsilon}}\left\{\alpha_{1} \Delta \sigma_{1}+\alpha_{2} \Delta \sigma_{2}\right\}
$$

where $\rho$ is the density, $C_{\varepsilon}$ is the specific heat, and $\alpha_{i}, \Delta \sigma_{i}$ are the coefficient of thermal expansion and cyclic stress for the orthotropic ply in the $i$ direction, respectively. Equation (2) assumes that adiabatic conditions are present and that second order effects can be ignored. Equation (1) can now be rewritten as:

$$
S=\frac{e B f(T)}{\rho C_{\varepsilon}}\left\{\alpha_{1} \Delta \sigma_{1}+\alpha_{2} \Delta \sigma_{2}\right\}
$$

The development of a uniform distribution of transverse intralaminar matrix cracks will result in significant changes in only two of the terms in equation (3). Numerous authors have shown that $\Delta \sigma_{i}$ change due to the development of damage in composite laminates, and others have shown that the laminate coefficients of thermal expansion also change. Damage-induced changes in $S$ can now be expressed as:

$$
\bar{S}=\frac{S}{S^{\circ}}=\frac{\left\{\alpha_{1} \Delta \sigma_{1}+\alpha_{2} \Delta \sigma_{2}\right\}}{\left\{\alpha_{1}^{0} \Delta \sigma_{1}^{0}+\alpha_{2}^{o} \Delta \sigma_{2}^{o}\right\}}
$$




\section{http://dx.doi.org/10.21611/qirt.1992.027}

where $\bar{S}$ is the normalized TSA signal, $S$ and $S^{\circ}$ are the current and original average TSA signal for the laminate, and $\alpha_{i} \Delta \sigma_{i}, \alpha_{i}{ }^{\prime}$ and $\Delta \sigma_{i}^{\circ}$ are the current and original ply coefficient of thermal expansion and cyclic stress in the $i^{\text {th }}$ direction, respectively.

A new theoretical model was developed to relate the damage-induced changes in $E_{x x}$ and $v_{x y}$ to $\bar{S}$ for laminates undergoing distributed transverse matrix cracking. Damage in cross-ply laminates was assumed to occur in the $90^{\circ}$ plies and consist only of a uniform distribution of transverse matrix cracks. The development of transverse matrix cracks in a ply is assumed to reduce the transverse lamina stiffness $E_{22}$ and transverse lamina coefficient of thermal expansion $\alpha_{2}$, and to have no effect on $E_{11}, v_{12}$ and $\alpha_{1}$. $E_{22}$ and $\alpha_{2}$ can now be expressed as:

$$
\begin{aligned}
& E_{22}=E_{22}{ }^{\circ}(1-D) \\
& \alpha_{2}=\alpha_{2}{ }^{\circ}(1-D)
\end{aligned}
$$

where $D$ is a damage parameter that varies between 0 and 1 , and $E_{22}{ }^{\circ}$ and $\alpha_{2}{ }^{\circ}$ are the undamaged lamina transverse stiffness and coefficient of thermal expansion, respectively. The minor Poisson's ratio $v_{21}$ of the damaged lamina can be written as:

$$
v_{21}=\frac{E_{22}}{E_{11}} v_{12}=v_{21}{ }^{\circ}(1-D)
$$

Classical lamination theory (CLT) was now employed to determine the dependence of the ply stresses on the damage parameter $D$. The thermoelastically-induced temperature change corresponding to a given value of $D$ for each ply of a laminate was found using the ply stresses and the results of equation (6) in equation (2). This approach was used to find $\Delta T$ for each ply in the laminate.

Equations (2) to (4) were developed for plies under adiabatic conditions. However, WONG [9] has shown that laminates can exhibit substantial conduction under typical loading frequencies. DUNN [10] has also shown that the thin coating of pure epoxy present on most composite laminates can significantly influence conduction in the laminate and must be considered in TSA of composites. Thus the thermoelastically-induced temperature changes corresponding to a given value of $D$ were used in Dunn's conduction model [10] to obtain the TSA signal on the surface of the laminate. The normalized TSA signal $\bar{S}$ was then based on these results; however, little conduction was predicted to occur for the laminates and loading conditions under consideration.

$E_{X X}$ and $v_{x y}$ for the laminate were also formulated using CLT, and each was linearly related to the damage parameter $D$. The above relationships were numerically evaluated for values of $D$ between 0 and 1 to obtain plots of normalized laminate stiffness ( $\bar{E}_{x x}$ ) and normalized Poisson's ratio $\left(\bar{v}_{x y}\right)$ versus $S$, where $E_{x x}$ and $v_{x y}$ are normalized by the original laminate stiffness and Poisson's ratio, respectively.

\section{Experimental results}

$\left(0_{3} / 90_{3}\right)_{s}$ S-2 Gl/Ep laminates were used to verify the theoretical developments of this work. Lamina longitudinal and transverse stiffness $E_{11}$ and $E_{22}$, Poisson's ratio $v_{12}$ and coefficients of thermal expansion $\alpha_{1}$ and $\alpha_{2}$ were measured, and the values are given in table $I$. Other relevant material properties were estimated using results for similar materials, and these properties are also given in table $I$.

The general experimental procedure for monitoring $E_{x x}, v_{x y}$, and TSA signal $S$ was as follows:

initial values for $S, E_{x x}$ and $v_{x y}$ were measured;

the specimen was step-loaded under uniaxial tension to induce damage;

after each step-loading values for $S, E_{x x}$ and $v_{x y}$ were determined; 
the second and third steps were repeated until multiple delaminations formed, at which time the test was concluded.

\subsection{TSA signal measurements}

The $\left(0_{3} / 90_{3}\right)_{\mathrm{s}} \mathrm{Gl} / \mathrm{Ep}$ laminates were $250 \mathrm{~mm}$ long, $19 \mathrm{~mm}$ wide and $1.9 \mathrm{~mm}$ thick, and each had adhesively bonded and beveled tabs for uniform load introduction. The front face of each specimen was lightly sanded with a fine grit paper prior to testing to ensure a uniform laminate emissivity. No special coating was applied to enhance emissivity.

The TSA signal was measured using a scanning infrared camera and a servohydraulic closed-loop testing machine. A non destructive cyclic stress range $\Delta \sigma_{x}=26 \mathrm{MPa}$ with $R=0.1$ and $21 \mathrm{~Hz}$ loading frequency was used during scanning. The largest possible region of each specimen was scanned while avoiding the end tabs and the rubber bands used to hold the extensometer. The laminate TSA signal was obtained after each damaging stress $\sigma_{d}$ was applied by averaging the TSA signals corresponding to many points on the laminate. Figure 1 shows $\bar{S}$ versus $\sigma_{d}$ for the $\left(0_{3} / 90_{3}\right)_{s}$ laminates, which exhibit a reasonable amount of scatter. The TSA signal is seen to increase with damaging load levels, as previously predicted.

\subsection{Stiffness and Poisson's ratio measurements}

The longitudinal stiffness and Poisson's ratio for each laminate were determined after each damaging load was applied. Extensometers were used to record the laminate strains, and a workstation and pen plotter obtained and analyzed the resulting load and strain data. Epoxy tabs were used as a base for the knife edges of the $25.4 \mathrm{~mm}$ longitudinal extensometer, and internal springs held the diametral extensometer to the specimen. Figures 2 and 3 show $\bar{E}_{x x}$ and $\bar{v}_{x y}$ versus $\sigma_{d}$ for the laminates, and both measures are seen to decrease with increasing levels of damage.

\section{Discussion and comparison of theoretical and experimental results}

Figures 4 and 5 show the theoretical predictions and experimental results for $\bar{E}_{x x}$ and $\bar{v}_{x y}$ versus $\bar{S}$ for the $\left(0_{3} / 90_{3}\right)_{\text {s }}$ laminates. There is very good correlation between the damage model and the experimental results, and the extent of scatter in the data is reasonable. Another useful check of the theoretical approach is seen in figure 6 , which presents the theoretical predictions and experimental results for $\bar{E}_{x y}$ versus $\bar{v}_{x y}$. Again there is a very good correlation between the theoretical predictions and experimental results.

The theoretical developments in this work are directed toward relating TSA signal changes to other measures of damage for laminated composite specimens subjected to transverse matrix cracking. Additional theoretical work will be necessary to model other forms of damage such as delaminations and fiber fractures, and other types of composites such as random-fiber composites. However, the theoretical developments can be used to quantify damage in any layup that undergoes transverse matrix cracking, regardless of the material properties.

Additional work relating $\bar{S}$ to the density of the transverse microcracks has yielded very good results, and other materials and layups have also been modeled successfully. This approach is now being extended to laminates under random loading.

\section{Conclusions}

It has been shown that normalized TSA signal changes can be used to quantify the level of transverse matrix cracking in composite laminates. This new approach can also be related to more traditional, but less convenient measures of damage such as changes in stiffness and Poisson's ratio. Additionally, this approach is valid for both laboratory specimens and full-scale composite structures, thereby providing a new theoretical and experimental methodology for quantifying damage in composites. 


\section{REFERENCES}

[1] ALLEN (D.H.), HARRIS (C.E.) and GROVES (S.E.). - A thermomechanical constitutive theory for elastic composites with distributed damage -1. Theoretical development. Int. J. of Solids and Struct., 23, 1987, p. 1301-1318.

[2] JAMISON (R.D.) et al. -Characterization and analysis of damage mechanisms in tensiontension fatigue of graphite/epoxy laminates. Effects of Defects in Composite Materials, ASTM STP 836, ASTM, Philadelphia, 1984, p. 21-55.

[3] REIFSNIDER (K.L.). - The critical element model: A modeling philosophy. Eng. Fract. Mech., 25, 1986, p. 739-749.

[4] DANIEL (I.M.) and CHAREWICZ (A.). - Fatigue damage mechanisms and residual properties of graphite/epoxy laminates. Eng. Fract. Mech., 25, 1986, p. 793-808.

[5] SMITH (P.A.) and WOOD (J.R.). - Poisson's ratio as a damage parameter in the static tensile loading of simple crossply laminates. Comp. Sci. and Tech., 38, 1990, p. 85-93.

[6] BOWLES (D.E.). - Effect of microcracks on the thermal expansion of composite laminates. J. Comp. Mat., 17, 1984, p. 173-187.

[7] ZHANG (D.) and SANDOR (B.I.). -Damage evaluation in composite materials using thermographic stress analysis. Advances in Fatigue Lifetime Predictive Techniques, ASTM STP 1122, R. Mitchell and R.W. Landgraf, Eds., ASTM, Philadelphia, 1992, p. 341-353.

[8] POTTER (R.T.) and GREAVES (L.J.). - The application of thermoelastic stress analysis techniques to fbre composites. Conf. Opti. and Opto-electr. Appl. Sci. and Eng. San Diego, SPIE, Vol. 817, 1987, p. 134-146.

[9] WONG (A.K.). - A non-adiabatic thermoelastic theory for composite laminates. J. Ph. Chem. of Solids, 52, 1991, p. 483-494.

[10] DUNN (S.A.). -Analysis of thermal conduction effects on thermoelastic temperature measurements for composite materials. To be published J. of Appl. Mech., 1992.

[11] 3M CORP. - Tech. Data, Type 1002 and 1003 Scotchply reinforced plastic. St. Paul, Minnesota, 1991.

\begin{tabular}{|c|c|c|c|}
\hline \multicolumn{4}{|c|}{$\begin{array}{l}\text { Table I } \\
\text { Material properties for GVEp and epoxy coating }\end{array}$} \\
\hline \multicolumn{2}{|c|}{ Property } & Gl/Ep & Epoxy \\
\hline $\begin{array}{l}E_{11} \\
E_{22} \\
v_{12} \\
\alpha_{1} \\
\alpha_{2} \\
t \\
C_{\varepsilon} \\
\rho \\
K \\
\end{array}$ & $\begin{array}{l}(\mathrm{GPa}) \\
(\mathrm{GPa}) \\
\\
\left(\mu \varepsilon^{0} \cdot \mathrm{K}^{-1}\right) \\
\left(\mu \varepsilon^{0} \cdot \mathrm{K}^{-1}\right) \\
(\mathrm{mm}) \\
\left(\mathrm{J} \cdot \mathrm{kg}^{-1} \cdot \mathrm{K}^{-1}\right) \\
\left(\mathrm{kg}^{-1} \mathrm{~m}^{-3}\right) \\
\left(\mathrm{m}^{2} \cdot \mathrm{s}^{-1}\right) \\
\end{array}$ & $\begin{array}{l}40.3 \\
13.0 \\
0.27 \\
5.7 \\
25.5 \\
0.18 \\
879.0[11] \\
1850.0[11] \\
2.1 \times 10^{-7}[11]\end{array}$ & $\begin{array}{l}4.8 \\
4.8 \\
0.35 \\
72.0[10] \\
72.0[10] \\
0.01[10] \\
1047.0[10] \\
1246.0[10] \\
1 \times 10^{-7}[10]\end{array}$ \\
\hline
\end{tabular}


http://dx.doi.org/10.21611/qirt.1992.027

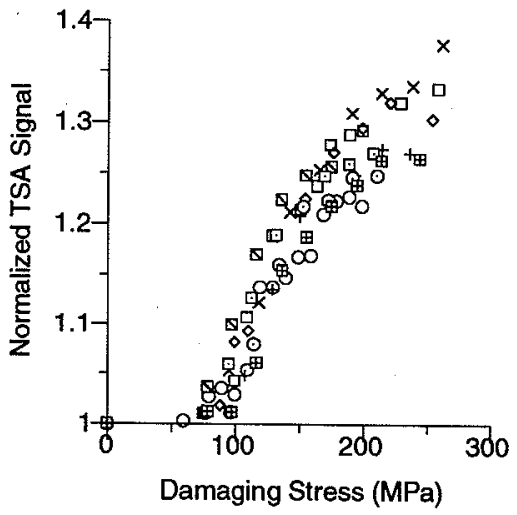

Figure 1. - Normalized TSA signal versus damaging stress, $\left(\mathrm{O}_{3} / 90_{3}\right)_{8}$ GI/Ep

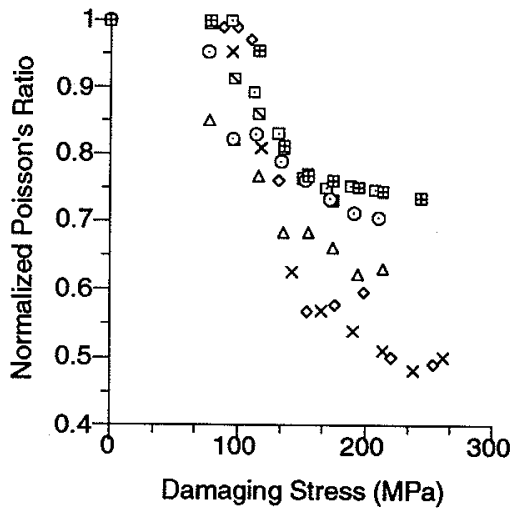

Figure 3. - Normalized Poisson's ratio versus damaging stress, $\left(\mathrm{O}_{3} / 90_{3}\right)_{s}$ Gl/Ep

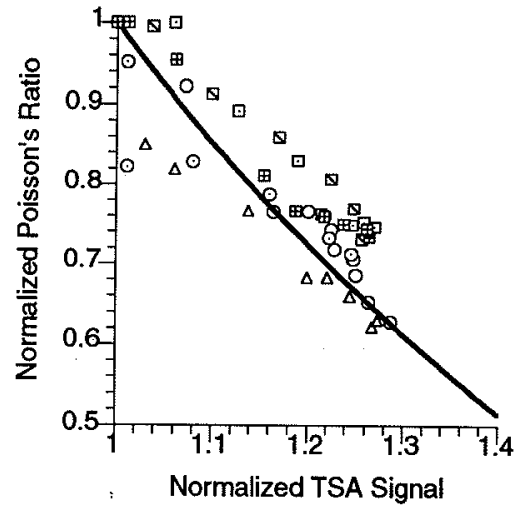

Figure 5. - Normalized Poisson's ratio versus normalized TSA signal, $\left(0_{3} / 90_{3}\right)_{8}$ GVEp

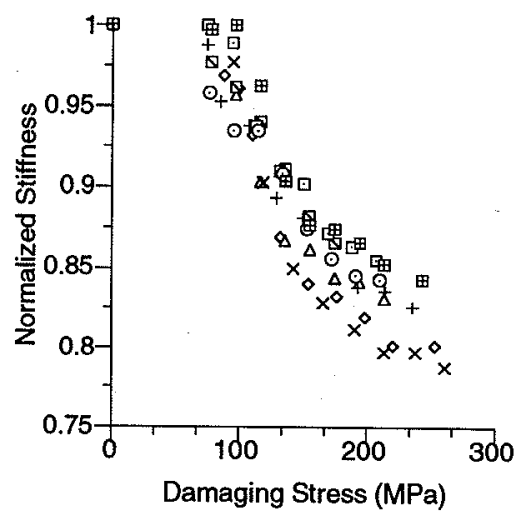

Figure 2. - Normalized stiffness versus damaging stress, $\left(\mathrm{O}_{3} / 90_{3}\right)_{\mathrm{s}} \mathrm{GI} / \mathrm{Ep}$

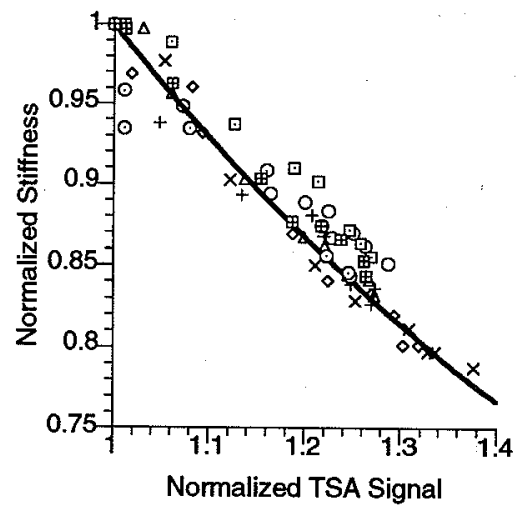

Figure 4. - Normalized stiffness versus normalized TSA Signal, $\left(0_{3} / 90_{3}\right)_{8}$ GVEp.

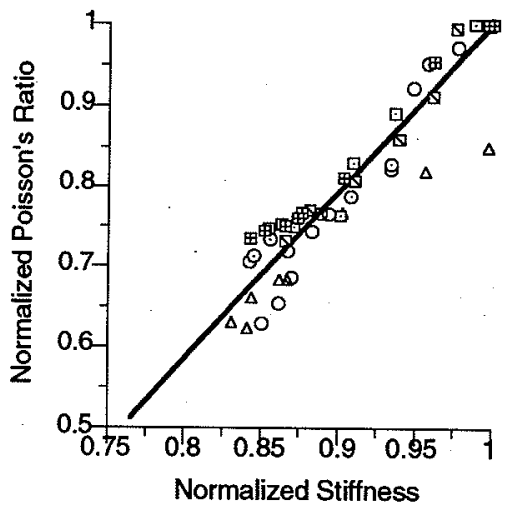

Figure 6. - Normalized Poisson's ratio versus normalized stiffness, $\left(0_{3} / 90_{3}\right)_{8}$ GI/Ep 